\title{
Physical activity and perceived barriers among high- school students in Muscat, Oman
}

\author{
R.M. Youssef, ${ }^{7}$ K. Al Shafie, ${ }^{1}$ M. Al-Mukhaini ${ }^{1}$ and H. Al-Balushi ${ }^{1}$
}

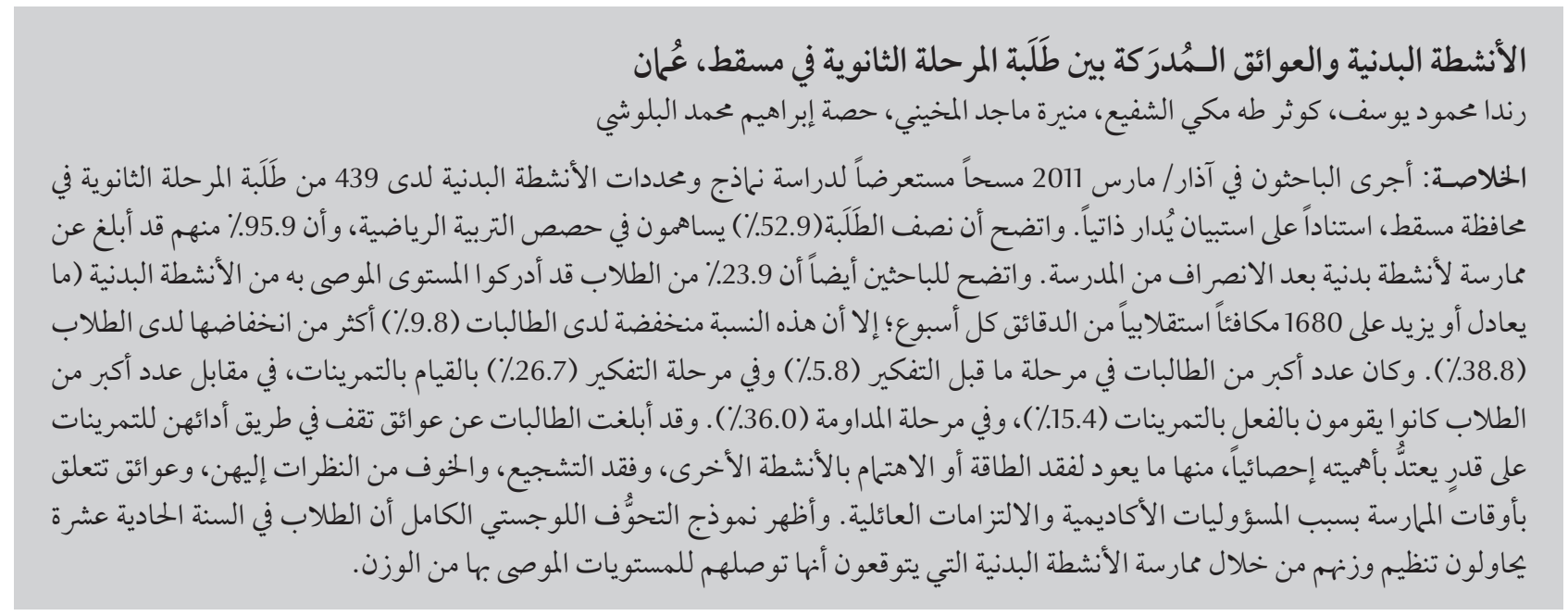

ABSTRACT A cross-sectional survey was conducted in March 2011 to study the patterns and determinants of physical activity among 439 secondary-school students in Muscat governorate based on a self-administered questionnaire. Half of the students (52.9\%) were enrolled in physical education classes and 95.9\% reported afterschool physical activities. The recommended level of physical activity ( $\geq 1680$ MET minutes/week) was met by $23.9 \%$ of students, being significantly lower among girls (9.8\%) than boys (38.8\%). More girls were in the stages of pre-contemplation (5.8\%) and contemplation (26.7\%) of adopting exercise while more boys were in the action (15.4\%) and maintenance stages (36.0\%). Girls reported significantly more barriers to exercise, related to lack of energy, interest in other activities, lack of encouragement, worries about looks, and time constraints from academic responsibilities and family obligations. The full model logistic regression revealed that boys, 11th-grade students and attempts to regulate weight significantly predicted physical activity meeting the recommended levels.

\section{Activité physique des lycéens et obstacles perçus par ces derniers à Mascate (Oman)}

RÉSUMÉ Une enquête transversale a été menée en mars 2011 pour étudier les caractéristiques et les facteurs déterminants de l'activité physique de 439 lycéens dans le gouvernorat de Mascate à l'aide d'un auto-questionnaire. La moitié des lycéens (52,9\%) ont été recrutés dans le cours d'éducation physique et 95,9\% déclaraient avoir des activités sportives après l'école. Le niveau d'activité physique recommandé ( $\geq 1680$ minutes MET [équivalence métabolique] par semaine) était atteint par 23,9\% des élèves, mais il était nettement inférieur chez les filles (9,8\%) que chez les garçons (38,8 \%). Les filles étaient plus nombreuses à être au stade de la pré-réflexion $(5,8 \%)$ et de la réflexion $(26,7 \%)$ au sujet de l'adoption d'une activité physique tandis que les garçons étaient plus nombreux à être au stade de l'action (15,4\%) et du maintien (36,0\%). Les filles déclaraient rencontrer davantage d'obstacles à la pratique d'une activité physique, tels qu'un intérêt pour d'autres activités, l'absence d'encouragement, l'inquiétude vis-à-vis du regard des autres, et des contraintes de temps par rapport aux obligations scolaires et familiales. Le modèle de régression logistique appliqué a permis de découvrir que le fait d'être un garçon, ou d'être en avant dernière année de lycée ou de tenter de réguler son poids étaient des facteurs fortement prédictifs d'une activité physique à la hauteur des niveaux recommandés. 


\section{Introduction}

Noncommunicable diseases (NCDs) have emerged as a global public health concern. Of the 56 million deaths that occurred in 2008, $63 \%$ were due to NCD and nearly $80 \%$ of these deaths occurred in low- and middle-income countries [1]. Oman is no exception, as $83 \%$ of the deaths that occurred in 2008 were due to NCD and $49 \%$ of these deaths were due to cardiovascular diseases [2]. The high rates of morbidity and mortality from chronic diseases threaten the gains in health and longevity achieved over the past 4 decades and the sustainability of the health-care system. Expenditure on health care in Oman rose by 64\% between 1995 and 2005 and by the year 2025 treatment of cardiovascular diseases alone is predicted to account for $21 \%$ of the total health-care expenditure [3].

The predominant factors in the emergence of NCD in Oman are assumed to be the changes in the nutritional habits of the population and the decline in habitual physical activities brought by the economic leap of the 1970s and 1980s [4]. Systematic analysis of population health data has revealed that these factors are amenable to modification [5-7] by implementing large-scale community intervention programmes focusing on increased physical activity and healthier food options, particularly for children [8]. Childhood can be a period of acquiring healthy habits that last across the lifespan and schools offer the best opportunity, as physical education is one of the 8 components of the school health programme [9] and nearly $25 \%$ of the Omani population between 5 and 15 years can be reached [10]. Despite the opportunities for exercise offered in Omani schools a study reported that only $23.3 \%$ of 7 th- to 10 th-grade students were physically active for 60 minutes per day [9]. Apparently the pattern of physical activities extends to late adolescence and adulthood, as a recent survey of college students revealed that only $30.7 \%$ of them were physically active for 60 minutes per day [11]. Anshel pointed to a number of factors that predict physical activity, including attitudes towards physical exercise, level and stage of motivation as well as the perceived barriers to exercising [12].

Previous studies in Oman have focused on the rates of physical activities and exercise, without addressing the determinants. Detailed investigation of the obstacles is indispensable for promoting physical activity among Omani children. This study aimed to describe the patterns and determinants of physical activity among secondary-school students and to identify the perceived barriers to exercise. The findings of the current study will guide the planning of relevant programmes promoting physical activity by addressing effectively the perceived barriers and the stage of motivation of schoolchildren.

\section{Methods}

A cross-sectional survey was conducted in March 2011 in Muscat governorate, targeting Omani students enrolled in secondary public schools.

\section{Sample}

The sampling frame consisted of a list of all secondary public schools in each educational region. The primary sampling unit was the educational region, the secondary sampling unit was the schools and the third was the classes. The unit of enquiry was school students enrolled in 11th and 12th grades. The sample size was estimated using the Epi Info program, version 2.3.1 [13], based on the number of students in 11th and 12th grades in Muscat governorate for the scholastic year 2010/11 $(n=$ 16676) [14] and prevalence of physical activity of $23.3 \%$ reported by the Global School Based Health Study [9], with a $5 \%$ degree of precision and a design effect of 1.5. Based on this assumption, the estimated minimum sample size was 405 students.

A multistage sampling technique was used to select schools and enrol students. Out of the 6 education regions, 4 with the highest population size were selected. From each region, 2 secondary public schools ( 1 for girls and 1 for boys) were randomly selected. Two classes (1 of each grade) were randomly selected from each school and all Omani national students were requested to participate. Non-Omani students were excluded.

\section{Data collection}

A self-administered, pre-tested and precoded questionnaire was developed for data collection in the classroom setting with the presence of one of the investigators. It included the demographic characteristics of students (10 questions), physical education classes in school (including the number and duration of classes per week), pattern of participation and types of activities (5 questions), the frequency and intensity of 14 types of out-of-school hours physical activities (15 questions) and the time spent in small-screen sedentary activities (2 questions). A set of 12 questions was used to assess the internal (6 questions) and external barriers (6 questions) to exercising $[15,16]$. All questions were negatively phrased with 5 responses ranging from strongly disagree (score 1) to strongly agree (score 5). Respondents were also asked about attempts to maintain or lose weight in the 30 days preceding the survey (2 questions). The weight and height of each student was obtained following standard procedures.

Students were informed about the purpose of the study and its implications for health programmes planning. Emphasis was placed on voluntary participation, the anonymity of the questionnaire and the confidentiality of the information during all phases of the study. The study was approved by the ethics committee at Sultan Qaboos 
University and the Ministry of Education and a written informed consent was obtained from students prior to data collection.

\section{Data analysis}

The intensity of all activities performed in after-school hours combined was calculated as the sum of each type of activity weighted by its energy equivalent and expressed as the metabolic equivalent of task (MET) per week as follows: MET minutes $/$ week $=\Sigma$ (energy equivalent of the task $x$ number of days $x$ duration per minute). The energy equivalent was 3.3 for walking, 4 for moderate activity and 8 for vigorous activity. Multiples of 1 MET indicated higher energy expenditure in a specific activity $[17,18]$. The recommendation of 60 minutes per day of moderate activity for school-age children [18,19], equivalent to $1680 \mathrm{MET}$ minutes/ week and calculated as $\Sigma(60$ minutes $\times 4$ MET $\times 7$ days) [20], was taken to classify students. "Physically active" students were those who accumulated $\geq 1680$ MET minutes/week while "physically inactive" were those who accumulated < 1680 MET minutes/ week.

Body mass index (BMI) was calculated from weight and height data and the participants were classified into underweight $\left(\mathrm{BMI}<18.5 \mathrm{~kg} / \mathrm{m}^{2}\right)$, normal weight (BMI 18.5-24.9 kg/m²), overweight (BMI 25-29.9 kg/ $\mathrm{m}^{2}$ ) and obese $\left(\mathrm{BMI}>30 \mathrm{~kg} / \mathrm{m}^{2}\right)$. The latter group was further classified into class 1 (BMI 30-34.9 kg/m²), class 2 (BMI $\left.35-39.9 \mathrm{~kg} / \mathrm{m}^{2}\right)$ and class 3 obesity $\left(\mathrm{BMI}>40 \mathrm{~kg} / \mathrm{m}^{2}\right)[21]$.

Separate scales were generated for internal and external barriers to exercising by summing the responses of the 6 related questions. The scores on each scale ranged from a minimum of 6 to a maximum of 30 . Higher scores reflected greater barriers to exercising. All items in each scale were positively correlated and the Cronbach alpha reliability for the scale of internal barriers was 0.59 and that for the scale of external barriers was 0.50 .

SPSS, version 16 was used for data analysis. The odds ratio (OR) and associated confidence interval (95\% CI) were computed. The chi-squared and the $t$-test for independent samples were the tests of significance used. Univariate and multivariate logistic regression analyses were used to identify the predictors of physical activity. The significance of the obtained results was judged at the $5 \%$ level.

\section{Results}

\section{Background characteristics}

The study included 439 students; 225 girls (51.2\%) and 214 boys (48.8\%), with 229 enrolled in 11 th grade $(52.2 \%)$ and 210 in 12 th grade $(47.8 \%)$. The majority were in the age group $15-<$ 17 years $(n=116 ; 26.4 \%)$ and $17-<$ 19 years $(n=309 ; 70.4 \%)$ while a few were in the age group 19-20 years ( $n$ $=14 ; 3.2 \%)$. The majority of students $(n=396 ; 90.2 \%)$ reported a monthly family income sufficient to cover their expenses, either with savings $(n=236$; $53.8 \%)$ or without savings $(n=160$; $36.5 \%$ ), while a small proportion reported a monthly family income insufficient in most $(n=29 ; 6.6 \%)$ or all months ( $n$ $=14 ; 3.2 \%)$.

Chronic health problems requiring medical care were reported by $25.3 \%$ of girls and $15.4 \%$ of boys. The most frequently reported health problems were anaemia (21.1\%), hereditary blood disorders (15.6\%), bronchial asthma (13.3\%), depression or anxiety (12.2\%), joint pain (12.2\%), diabetes mellitus (4.4\%) and hypertension (2.2\%) among others.

\section{Physical education during school hours}

Table 1 reveals that only half of the boys and girls (52.9\%) enrolled for physical education classes during school hours and the majority of them (91.4\%) opted for 80 minutes per week. However, considerable proportions of girls (45.5\%) and boys $(36.0 \%)$ were irregular in attending these physical education classes. Although boys were not significantly more likely to opt for physical education classes relative to girls ( $\mathrm{OR}=1.08 ; 95 \%$ CI: $0.74-1.57)$ they were 3 times more likely to attend physical education classes either always ( $\mathrm{OR}=3.78$; 95\% CI: 1.36-10.53) or sometimes ( $\mathrm{OR}=3.94$; 95\% CI: 1.51-10.31). Ball games were the predominant type of activity during physical education classes among boys and girls (91.8\%), with no difference between the sexes. Types of exercises more frequently reported by girls were jogging (39.7\%), aerobics (14.9\%) and rope jumping $(9.1 \%)$.

\section{Physical activity in after- school hours}

Physical activities in after-school hours for recreation or exercising were reported by $98.1 \%$ of boys and $93.8 \%$ of girls and it was 3.48 times (95\% CI: 1.05-12.75) more likely among boys (Table 2). Girls were nearly 3 times more likely to report walking ( $\mathrm{OR}=$ 3.11 ; 95\% CI: 1.97-4.90), climbing stairs $(\mathrm{OR}=2.80 ; 95 \% \mathrm{CI}: 1.70-4.62)$ and cycling (OR $=2.93$; 95\% CI: $1.92-$ 4.47). Boys were nearly 8 times ( $\mathrm{OR}=$ 8.29; 95\% CI: 4.50-15.46) more likely to report weight lifting and were nearly 3 times more likely to participate in ball games $(\mathrm{OR}=2.95,95 \% \mathrm{CI}=1.88-4.62)$ and swimming $(\mathrm{OR}=2.86 ; 95 \% \mathrm{CI}$ : 1.78-4.59). They were also more likely to report running $(\mathrm{OR}=1.92 ; 95 \% \mathrm{CI}$ : $1.27-2.92)$ and jogging $(\mathrm{OR}=1.83$; 95\% CI: 1.22-2.74). Less than a quarter of students (23.9\%) met the recommended level of physical activity equivalent to $\geq 1680$ MET minutes/week, and the rate was significantly lower among girls (9.8\%) than boys (38.8\%).

\section{Readiness to adopt regular exercising}

Enrolled students were at different stages of motivational readiness to adopt 


\begin{tabular}{|c|c|c|c|c|c|c|}
\hline \multirow[t]{2}{*}{ Physical education in school hours } & \multicolumn{2}{|c|}{ Boys } & \multicolumn{2}{|c|}{ Girls } & \multicolumn{2}{|c|}{ Total } \\
\hline & No. & $\%$ & No. & $\%$ & No. & $\%$ \\
\hline Participation in physical education classes & \multicolumn{2}{|c|}{$(n=214)$} & \multicolumn{2}{|c|}{$(n=225)$} & \multicolumn{2}{|c|}{$(n=439)$} \\
\hline No & 103 & 48.1 & 104 & 46.2 & 207 & 47.1 \\
\hline Yes & 111 & 51.9 & 121 & 53.8 & 232 & 52.9 \\
\hline Duration of exercise per week (min) & \multicolumn{2}{|c|}{$(n=111)$} & \multicolumn{2}{|c|}{$(n=121)$} & \multicolumn{2}{|c|}{$(n=232)$} \\
\hline 30 & 1 & 0.9 & 5 & 4.1 & 6 & 2.6 \\
\hline 80 & 104 & 93.7 & 108 & 89.2 & 212 & 91.4 \\
\hline 150 & 2 & 1.8 & 6 & 5.0 & 8 & 3.4 \\
\hline$\geq 240$ & 4 & 3.6 & 2 & 1.7 & 6 & 2.6 \\
\hline \multicolumn{7}{|l|}{ Type of exercise $^{a}$} \\
\hline Ball games ${ }^{\mathrm{b}}$ & 102 & 91.9 & 111 & 91.7 & 213 & 91.8 \\
\hline Jogging & 8 & 7.2 & 48 & 39.7 & 56 & 24.1 \\
\hline Aerobics & 3 & 2.7 & 18 & 14.9 & 21 & 9.1 \\
\hline Rope jumping & 0 & 0.0 & 11 & 9.1 & 11 & 4.7 \\
\hline Weight lifting & 4 & 3.6 & 1 & 0.8 & 5 & 2.2 \\
\hline Martial arts & 1 & 0.9 & 2 & 1.7 & 3 & 1.3 \\
\hline \multicolumn{7}{|l|}{ Frequency of participation } \\
\hline Rarely & 6 & 5.4 & 22 & 18.2 & 28 & 12.1 \\
\hline Sometimes & 34 & 30.6 & 33 & 27.3 & 67 & 28.9 \\
\hline Always & 71 & 64.0 & 66 & 54.5 & 137 & 59.0 \\
\hline
\end{tabular}

${ }^{a}$ Categories are not mutually exclusive.

bIncludes football, basketball and volleyball.

\begin{tabular}{|c|c|c|c|c|c|c|}
\hline \multirow[t]{2}{*}{ After-school hours activities } & \multicolumn{2}{|c|}{ Boys } & \multicolumn{2}{|c|}{ Girls } & \multirow[t]{2}{*}{ OR } & \multirow[t]{2}{*}{$95 \% \mathrm{Cl}$} \\
\hline & No. & $\%$ & No. & $\%$ & & \\
\hline $\begin{array}{l}\text { Participation in after-school } \\
\text { activities }\end{array}$ & \multicolumn{2}{|c|}{$(n=214$} & \multicolumn{2}{|c|}{$(n=225)$} & & \\
\hline No & 4 & 1.9 & 14 & 6.2 & & \\
\hline Yes & 210 & 98.1 & 211 & 93.8 & 3.48 & $1.05-12.75$ \\
\hline Types of activities ${ }^{a}$ & \multicolumn{2}{|c|}{$(n=210$} & \multicolumn{2}{|c|}{$(n=225)$} & & \\
\hline Walking & 117 & 55.7 & 168 & 79.6 & 0.32 & $0.20-0.51$ \\
\hline Climbing stairs & 140 & 66.7 & 179 & 84.8 & 0.36 & $0.22-0.59$ \\
\hline Ball games ${ }^{b}$ & 165 & 78.6 & 117 & 55.5 & 2.95 & $1.88-4.62$ \\
\hline Running & 143 & 68.1 & 111 & 52.6 & 1.92 & $1.27-2.92$ \\
\hline Jogging & 119 & 56.7 & 88 & 41.7 & 1.83 & $1.22-2.74$ \\
\hline Aerobics & 72 & 34.3 & 57 & 27.0 & 1.41 & $0.91-2.18$ \\
\hline Swimming & 81 & 38.6 & 38 & 18.0 & 2.86 & $1.78-4.59$ \\
\hline Weight lifting & 85 & 40.5 & 16 & 7.6 & 8.29 & $4.50-15.5$ \\
\hline Cycling & 61 & 29.1 & 115 & 54.5 & 0.34 & $0.22-0.52$ \\
\hline Rope jumping & 27 & 12.9 & 41 & 19.4 & 0.61 & $0.35-1.08$ \\
\hline Martial arts & 14 & 6.7 & 8 & 3.8 & 1.81 & $0.69-4.88$ \\
\hline Racket games ${ }^{\mathrm{c}}$ & 17 & 8.1 & 14 & 6.6 & 1.24 & $0.56-2.74$ \\
\hline Table tennis & 6 & 2.9 & 1 & 0.5 & 6.18 & $0.73-137.33$ \\
\hline
\end{tabular}

${ }^{a}$ Categories are not mutually exclusive.

${ }^{b}$ Includes football, basketball and volleyball.

Includes tennis and squash.

$O R=$ odds ratio; $C l=$ confidence interval. 
regular exercise. More than a third of students (39.0\%) had plans to exercise regularly within the next 6 months (preparation stage), 18.7\% would think of exercising regularly in the coming 6 months (contemplation phase) and $5.1 \%$ were not thinking of exercising regularly (pre-contemplation). A statistically significant difference was observed between boys and girls in this respect $\left(\chi_{4}^{2}=47.87, P=0.000\right)$. Higher percentages of girls were in the stages of pre-contemplation (5.8\%) and contemplation (26.7\%), while higher percentages of boys were in the action stage (15.4\%) of exercising regularly for $<6$ months and the maintenance stage $(36.0 \%)$ of exercising regularly for $>6$ months (Table 3).

\section{Small-screen recreational activities}

As for small-screen recreational activities, $23.2 \%$ of students reported spending 3-7 hours daily watching television and $29.2 \%$ of them reported spending 3-7 hours daily on computer activities (Table 3).

\section{Body weight and attempts to control weight}

More than a quarter of students were overweight (14.1\%) or obese (13.0\%). Attempts to lose or control weight in the 30 days preceding the survey was reported by $56.0 \%$ of boys and $48.1 \%$ of girls. Exercising was the most frequently cited method of losing weight, while food restriction and starving for a day or more were the next most common methods (Table 4). Relative to students with normal BMI, obese students were 1.75 times (95\% CI: 1.03-2.97) more likely to report never participating in physical education classes ( $42.5 \%$ compared with 55.6\%) and 4.89 times (95\% CI: 2.83-8.47) more likely to report attempts to control or lose weight in the last 30 days ( $42.5 \%$ compared with $55.6 \%)$.

\section{Perceived barriers to exercising}

Variable proportions of students expressed agreement with statements representing barriers to exercising. Regarding internal barriers, substantial proportions of students expressed agreement that other recreational activities were more entertaining than exercising (72.2\%), having limited energy to exercise (43.3\%) and thinking that exercise was difficult and too tiring (40.1\%). Only $18.0 \%$ were not thinking that exercise has positive health effects. As for external barriers, a high proportion of students agreed that parents give priority to academic success (71.5\%) or that they lacked leisure time due to academic responsibilities (65.4\%). Other perceived external barriers were lack of exercise equipment in the home (53.5\%) and lack of leisure time because of social and family responsibilities (39.6\%).

The mean scores of students on the scale measuring internal and external barriers for exercising were low ( $\mathrm{Ta}-$ ble 5). The mean scores of girls was significantly higher than that of boys on the scale measuring internal barriers [14.2 (SD 0.27$)$ versus 13.4 (SD $0.25)](P=0.023)$ and external barriers for exercising [16.1 (SD 0.26) versus $14.9(\mathrm{SD} 0.25)](P=0.001)$. The scores

\begin{tabular}{|c|c|c|c|c|c|c|}
\hline \multirow{2}{*}{$\begin{array}{l}\text { Time spent in sedentary activities/stage of } \\
\text { motivation }\end{array}$} & \multicolumn{2}{|c|}{ Boys $(n=214)$} & \multicolumn{2}{|c|}{ Girls $(n=225)$} & \multicolumn{2}{|c|}{ Total $(n=439)$} \\
\hline & No. & $\%$ & No. & $\%$ & No. & $\%$ \\
\hline \multicolumn{7}{|l|}{ Daily time spent watching television (hours) } \\
\hline$<0.5$ & 48 & 22.4 & 49 & 21.8 & 97 & 22.1 \\
\hline $1-2$ & 121 & 56.5 & 119 & 52.9 & 240 & 54.7 \\
\hline $3-4$ & 29 & 13.6 & 41 & 18.2 & 70 & 15.9 \\
\hline $5-7$ & 16 & 7.5 & 16 & 7.1 & 32 & 7.3 \\
\hline \multicolumn{7}{|l|}{ Daily time spent on computer (hours) } \\
\hline$<0.5$ & 65 & 30.4 & 62 & 27.6 & 127 & 28.9 \\
\hline $1-2$ & 92 & 43.0 & 92 & 40.9 & 184 & 41.9 \\
\hline $3-4$ & 30 & 14.0 & 30 & 13.3 & 60 & 13.7 \\
\hline $5-7$ & 27 & 12.6 & 41 & 18.2 & 68 & 15.5 \\
\hline \multicolumn{7}{|l|}{ Stage of motivation for adopting exercise } \\
\hline Pre-contemplation & 10 & 4.7 & 13 & 5.8 & 23 & 5.1 \\
\hline Contemplation & 22 & 10.3 & 60 & 26.7 & 82 & 18.7 \\
\hline Preparation & 72 & 33.6 & 99 & 44.0 & 171 & 39.0 \\
\hline Action & 33 & 15.4 & 27 & 12.0 & 60 & 13.7 \\
\hline Maintenance & 77 & 36.0 & 26 & 11.5 & 103 & 23.5 \\
\hline
\end{tabular}




\begin{tabular}{|c|c|c|c|c|c|c|}
\hline \multirow{2}{*}{ Body weight and attempt at weight loss } & \multicolumn{2}{|c|}{ Boys } & \multicolumn{2}{|c|}{ Girls } & \multicolumn{2}{|c|}{ Total } \\
\hline & No. & $\%$ & No. & $\%$ & No. & $\%$ \\
\hline Classification of body weight & \multicolumn{2}{|c|}{$(n=212)$} & \multicolumn{2}{|c|}{$(n=221)$} & \multicolumn{2}{|c|}{$(n=433)^{\mathrm{a}}$} \\
\hline Underweight & 50 & 23.6 & 45 & 20.4 & 95 & 21.9 \\
\hline Normal & 111 & 52.3 & 110 & 49.8 & 221 & 51.0 \\
\hline Overweight & 27 & 12.7 & 34 & 15.4 & 61 & 14.1 \\
\hline Obese class 1 & 18 & 8.5 & 16 & 7.2 & 34 & 7.9 \\
\hline Obese class 2 & 5 & 2.4 & 12 & 5.4 & 17 & 3.9 \\
\hline Obese class 3 (morbid) & 1 & 0.5 & 4 & 1.8 & 5 & 1.2 \\
\hline Attempts to control weight (in last 30 days) & \multicolumn{2}{|c|}{$(n=214)$} & \multicolumn{2}{|c|}{$(n=225)$} & \multicolumn{2}{|c|}{$(n=439)$} \\
\hline No & 111 & 51.9 & 99 & 44.0 & 210 & 47.8 \\
\hline Yes $^{b}$ & 103 & 48.1 & 126 & 56.0 & 229 & 52.2 \\
\hline Methods of weight control ${ }^{b, c}$ & \multicolumn{2}{|c|}{$(n=103)$} & \multicolumn{2}{|c|}{$(n=126)$} & \multicolumn{2}{|c|}{$(n=229)$} \\
\hline Exercising & 72 & 69.9 & 65 & 51.6 & 137 & 59.8 \\
\hline Food restriction & 35 & 34.0 & 60 & 47.6 & 95 & 41.5 \\
\hline Starving for days & 1 & 1.0 & 10 & 7.9 & 11 & 4.8 \\
\hline Slimming pills & 1 & 1.0 & 4 & 3.2 & 5 & 2.2 \\
\hline +Induction of vomiting & 0 & 0.0 & 2 & 1.6 & 2 & 0.9 \\
\hline
\end{tabular}

${ }^{a} 6$ cases were excluded due to missed information.

${ }^{b}$ Categories are not mutually exclusive;

Denominator is total attempting to control weight;

of girls were significantly higher than $\quad 0.0001)$, and worries about looks $(P<\quad(P<0.0001)$ and limited leisure time those of boys on internal barriers related 0.0001$)$. Their scores were significantly because of academic responsibilities to lack of energy $(P=0.014)$, interest higher on external barriers related to $\quad(P<0.0001)$ and family obligations $(P$ in other recreational activities $(P<$ lack of encouragement for exercising $=0.039)$.

\begin{tabular}{|c|c|c|c|c|c|}
\hline \multirow[t]{2}{*}{ Barrier and stage of motivation } & \multicolumn{2}{|c|}{ Boys $(n=214)$} & \multicolumn{2}{|c|}{ Girls $(n=225)$} & \multirow[t]{2}{*}{$P$-value } \\
\hline & Mean score & SE & Mean score & SE & \\
\hline \multicolumn{6}{|l|}{ Internal barrier } \\
\hline Total & 13.36 & 0.25 & 14.21 & 0.27 & 0.023 \\
\hline Thinking exercise is difficult and too tiring & 2.35 & 0.08 & 2.22 & 0.07 & 0.252 \\
\hline Never having energy for exercise & 1.79 & 0.06 & 2.03 & 0.07 & 0.014 \\
\hline Other recreational activities are more entertaining & 3.01 & 0.08 & 3.48 & 0.09 & 0.000 \\
\hline Not thinking that exercise has positive health effects & 1.82 & 0.08 & 1.65 & 0.07 & 0.116 \\
\hline Worrying about looks when exercising & 1.94 & 0.07 & 2.32 & 0.08 & 0.000 \\
\hline Limited abilities to exercise & 2.45 & 0.08 & 2.51 & 0.08 & 0.595 \\
\hline \multicolumn{6}{|l|}{ External barrier } \\
\hline Total & 14.91 & 0.25 & 16.13 & 0.26 & 0.001 \\
\hline No fitness centre to exercise & 2.21 & 0.08 & 2.17 & 0.08 & 0.767 \\
\hline No exercise equipment at home & 2.74 & 0.09 & 2.75 & 0.08 & 0.945 \\
\hline No encouragement to exercise & 1.76 & 0.07 & 2.13 & 0.08 & 0.000 \\
\hline Parents give priority to academic success & 3.15 & 0.08 & 3.18 & 0.08 & 0.775 \\
\hline No leisure time because of academic responsibilities & 2.80 & 0.09 & 3.43 & 0.08 & 0.000 \\
\hline No leisure time because of social \& family responsibilities & 2.25 & 0.07 & 2.47 & 0.08 & 0.039 \\
\hline
\end{tabular}

$S E=$ standard error . 


\section{Determinants of physical activity in after-school hours}

Table 6 illustrates the determinants of physical activity in after-school hours. The recommended level of physical activity was 5 times more likely to be met by boys $(\mathrm{OR}=5.85$; $95 \%$ CI: 3.48 9.82). It was also more likely to be met by students in 11th grade $(\mathrm{OR}=1.78 ; 95 \%$ CI: 1.13-2.79), those who attempted to control or lose weight in the 30 days preceding the survey $(\mathrm{OR}=1.60 ; 95 \% \mathrm{CI}$ : $1.02-2.50$ ) as well as those who opted for exercise to lose or control their body weight $(\mathrm{OR}=2.15$; 95\% CI: $1.32-3.52$ ). Students in the maintenance stage of motivation readiness were 3 times more likely to meet the recommended level of physical activity relative to those in the pre-contemplation stage $(\mathrm{OR}=3.14$; 95\% CI: 1.08-9.10). In contrast, higher scores on the scale measuring external barriers to exercise lowered the likelihood of meeting the recommended level of physical activity $(\mathrm{OR}=0.93$; 95\% CI: 0.88-0.98).

\section{Independent determinants of physical activity}

Physical activity in after-school hours was modelled as a function of the scores on the scale measuring internal and external barriers as well as the significant determinants identified in univariate analysis (Table 7). The stage of motivation for adopting physical activity was excluded as it was related to the scores on the scale measuring barriers to exercise. Adjusted for other factors, the model revealed that boys, 11 th-grade students and those who attempted to control or lose weight significantly increased the likelihood of physical activity meeting the recommended levels. Scores on the scale measuring internal and external barriers for exercise fell just behind significance. This model classified correctly $75.9 \%$ of students who met the recommended levels of physical activities and explained $21.1 \%$ of the variability between physically active and physically inactive students.

\section{Discussion}

Health promotion activities by the government of Oman focus on physical activity at school [9] and in the community [22]. Although physical education is an integral part of the school health programme it is not part of the core curriculum. Half of the students enrolled in our study opted for physical education classes at school and only $59.0 \%$ of them were attending classes regularly. This finding reflects the lack of students' interest in physical education classes that engage them mostly in ball games. It also indicates the limited role of schools in fostering an acceptable level of physical activities, as those students who were regular in attending physical education classes were not more likely to be physically active in after-school hours. It has been shown that the success of schools in promoting physical activity is not so much accomplished by providing physical education classes but by having a written policy defining goals to be achieved through specific plans to increase students' level of physical activity [23] and by providing diverse activities to attract and maintain students' interest in physical education classes. Haug et al. pointed to the higher likelihood of participation in physical activities among students attending schools with multiple facilities, playgrounds and weight-lifting equipment [24].

A minimum of 60 minutes per day of moderate physical activity or its equivalent of vigorous activity is recommended for school-age children to achieve beneficial effects on physical and mental health $[18,19,25,26]$. Our study revealed that the majority of students reported different types of physical activities but less than a quarter met the recommended level equivalent to $1680 \mathrm{MET}$ minutes/week. This rate is similar to the national figure of $23.3 \%$ among 7 th- to 10 th-grade students reported in 2005 using different methods [9]. Nearly a quarter of students reported spending 3 or more hours in small-screen recreational activities, namely watching television (23.2\%) and computer-related activities (29.2\%), which is slightly lower than the $34.1 \%$ reported by the Global School Health Survey in Oman in 2005 [9]. Rosenberg et al. demonstrated that the accessibility of electronic equipment such as television and computers was associated with sedentary behaviour among children [27].

Obesity is of major concern in Oman and it has its roots during the childhood period. In 2008, estimates revealed that $55.8 \%$ of the Omani population were overweight and another 20.9\% were obese [2]. Among university students, the combined prevalence of overweight and obesity was $28.2 \%$ [11]. More than a quarter of students in this study were overweight or obese and the rate was higher among girls than boys. Students seem to be aware of their body image, as a half of the boys and girls reported that they were attempting to lose weight or maintain a normal body weight using different means. This study, as well as that of Chen et al., revealed that the desire to lose weight or maintain an ideal body weight increased the likelihood of participating in physical activity [28].

Generally the level of perceived barriers for exercising was low and the perception of the beneficial effects of exercising was high. The most prominent internal barriers were a high interest in activities other than exercising and a lack of energy. This study, as well as others, underscored the role of external barriers as a deterrent to exercising, notably time constraints because of academic obligations [15,29-31] and priority given to academic success $[29,30]$. This was particularly true for 12th-grade students, whose future career depends on their achievement in this final school year. These students can overcome time constraints by integrating physical activity into their daily routine with the added knowledge of its favourable impact on school achievement. 


\begin{tabular}{|c|c|c|c|c|c|c|}
\hline \multirow{2}{*}{$\begin{array}{l}\text { Determinants of recommended level of } \\
\text { physical activity }\end{array}$} & \multicolumn{2}{|c|}{ Inactive $(n=334)$} & \multicolumn{2}{|c|}{ Active $(n=105)$} & \multirow[t]{2}{*}{ OR } & \multirow[t]{2}{*}{$95 \% \mathrm{Cl}$} \\
\hline & No. & $\%$ & No. & $\%$ & & \\
\hline \multicolumn{7}{|l|}{ Sex } \\
\hline Male & 203 & 60.8 & 22 & 20.9 & 1 & \\
\hline Female & 131 & 39.2 & 83 & 79.1 & 5.85 & $3.48-9.82$ \\
\hline \multicolumn{7}{|l|}{ Age group (years) } \\
\hline 15-16 & 79 & 23.6 & 37 & 35.2 & 1.63 & $0.36-7.46$ \\
\hline $17-18$ & 243 & 72.8 & 66 & 62.9 & 2.81 & $0.59-13.20$ \\
\hline $19-20$ & 12 & 3.6 & 2 & 1.9 & 1 & \\
\hline \multicolumn{7}{|l|}{ Education grade } \\
\hline Grade 11 & 163 & 48.8 & 66 & 62.9 & 1.78 & $1.13-2.79$ \\
\hline Grade 12 & 171 & 51.2 & 39 & 37.1 & 1 & \\
\hline \multicolumn{7}{|l|}{ Family income } \\
\hline Sufficient & 302 & 90.4 & 94 & 89.5 & 1 & \\
\hline Insufficient & 32 & 9.6 & 11 & 10.5 & 1.10 & $0.54-2.28$ \\
\hline \multicolumn{7}{|l|}{ Chronic health problems } \\
\hline Yes & 72 & 21.6 & 18 & 17.1 & 1 & \\
\hline No & 262 & 78.4 & 87 & 82.9 & 1.33 & $0.75-2.35$ \\
\hline \multicolumn{7}{|l|}{ Physical education in school } \\
\hline Never & 157 & 47.0 & 50 & 47.6 & 1 & \\
\hline Rarely or sometimes & 74 & 22.2 & 21 & 20.0 & 0.89 & $0.50-1.59$ \\
\hline Always & 103 & 30.8 & 34 & 32.4 & 1.04 & $0.63-1.71$ \\
\hline \multicolumn{7}{|l|}{ Daily time spent watching television (hours) } \\
\hline$<0.5$ & 69 & 20.6 & 28 & 26.7 & 1 & \\
\hline $1-2$ & 193 & 57.8 & 47 & 44.8 & 0.60 & $0.35-1.03$ \\
\hline $3-4$ & 46 & 13.8 & 24 & 22.8 & 1.29 & $0.66-2.49$ \\
\hline $5+$ & 26 & 7.8 & 6 & 5.7 & 0.57 & $0.21-1.53$ \\
\hline \multicolumn{7}{|l|}{ Daily time spent on computer (hours) } \\
\hline$<0.5$ & 96 & 28.7 & 31 & 29.5 & 1 & \\
\hline $1-2$ & 143 & 42.8 & 41 & 39.1 & 0.89 & $0.52-1.51$ \\
\hline $3-4$ & 47 & 14.1 & 13 & 12.4 & 0.86 & $0.41-1.79$ \\
\hline $5-7$ & 48 & 14.4 & 20 & 19.0 & 1.29 & $0.67-2.50$ \\
\hline \multicolumn{7}{|l|}{ Body weight classification $^{a}$} \\
\hline Overweight or obese & 86 & 26.1 & 31 & 30.1 & 1 & \\
\hline Normal & 168 & 50.9 & 53 & 51.5 & 0.90 & $0.36-1.33$ \\
\hline Underweight & 76 & 23.0 & 19 & 18.4 & 0.69 & $0.36-1.33$ \\
\hline \multicolumn{7}{|l|}{ Attempt to control weight (in last 30 days) } \\
\hline No & 169 & 50.6 & 41 & 39.0 & 1 & \\
\hline Yes & 165 & 49.4 & 64 & 61.0 & 1.60 & $1.02-2.50$ \\
\hline \multicolumn{7}{|l|}{ Method of weight control } \\
\hline None & 169 & 50.6 & 41 & 39.0 & 1 & \\
\hline Other methods & 75 & 22.5 & 17 & 16.2 & 0.93 & $0.49-3.52$ \\
\hline Exercising & 90 & 26.9 & 47 & 44.8 & 2.15 & $1.32-3.52$ \\
\hline \multicolumn{7}{|c|}{ Motivation stage for adopting physical activity } \\
\hline Pre-contemplation & 18 & 5.4 & 5 & 4.8 & 1 & \\
\hline Contemplation & 75 & 22.4 & 7 & 6.7 & 0.34 & $0.96-1.18$ \\
\hline Preparation & 146 & 43.7 & 25 & 23.8 & 0.62 & $0.21-1.81$ \\
\hline Action & 40 & 12.0 & 20 & 19.0 & 1.80 & $0.58-5.55$ \\
\hline Maintenance & 55 & 16.5 & 48 & 45.7 & 3.14 & $1.08-9.10$ \\
\hline Barriers to physical activity & \multicolumn{2}{|c|}{ Mean (SD) } & \multicolumn{2}{|c|}{ Mean (SD) } & & \\
\hline Internal barriers & \multicolumn{2}{|c|}{$13.9(3.7)$} & & & 0.96 & $0.91-1.02$ \\
\hline External barriers & & & & & 0.93 & $0.88-0.98$ \\
\hline
\end{tabular}

${ }^{a} 6$ cases excluded due to missing information.

$S D=$ standard deviation; $O R=$ odds ratio; $C l=$ confidence interval. 


\begin{tabular}{|c|c|c|c|c|c|}
\hline Independent determinant & B & SE & Wald statistic & Adjusted OR & $95 \% \mathrm{Cl}$ \\
\hline \multicolumn{6}{|l|}{ Sex } \\
\hline \multicolumn{6}{|l|}{ Female $^{\mathrm{a}}$} \\
\hline Male & 1.809 & 0.275 & 43.24 & 6.11 & $3.56-10.47$ \\
\hline \multicolumn{6}{|l|}{ School grade } \\
\hline \multicolumn{6}{|l|}{ Grade $12^{a}$} \\
\hline Grade 11 & 0.532 & 0.250 & 4.523 & 1.70 & $1.04-2.78$ \\
\hline \multicolumn{6}{|c|}{ Attempt to control weight (in last 30 days) } \\
\hline \multicolumn{6}{|l|}{$\mathrm{No}^{\mathrm{a}}$} \\
\hline Yes & 0.601 & 0.251 & 5.719 & 1.82 & $1.12-2.99$ \\
\hline \multicolumn{6}{|l|}{ Barriers to physical activity } \\
\hline Internal barriers & -0.021 & 0.033 & 0.417 & 0.98 & 0.92-1.05 \\
\hline External barriers & -0.019 & 0.34 & 0.312 & 0.98 & $0.92-1.05$ \\
\hline
\end{tabular}

Model sensitivity $=75.9 \%$; Nagelkerke $R^{2}=21.1 \%$

${ }^{a}$ Reference category.

$S E=$ standard error; $O R=$ odds ratio; $C l=$ confidence interval.

Girls had greater internal barriers related to lack of energy, interest in activities other than exercising and worries about looks while exercising, as well as external barriers related to lack of encouragement and time constraints due to studies and family obligations. Worry about looks reflects low self-confidence [29] that should be challenged. The other barriers mirror the cultural norm in Oman that values home-centred activities for girls and encourages their involvement in household chores. These barriers are probably the reason for finding a significantly higher percentage of girls in the pre-contemplation and contemplation stage, which is subsequently reflected in their behaviour. Girls were less likely to participate in after-school hours activities, especially those of moderate and vigorous intensity such ball games, running, jogging and swimming. Less than one-tenth of girls met the recommended level of physical activity equivalent to 1680 MET minutes/week. The variation in the levels of physical activity between boys and girls has been previously reported from Oman [9] and elsewhere [28,32]. Rosenberg et al. demonstrated an inverse relationship between the presence of exercise equipment in the home and sedentary behaviour [27] and the use of such equipment at home may promote acceptable levels of physical activity among girls in Oman. Also encouragement will result in the desired behaviour through increasing girls' perception of their sports competence [33].

The use of metabolic equivalents to express the levels of physical activity allowed the identification of the proportion of students who met the recommended levels with a certain degree of objectivity. The use of a selfadministered, pretested questionnaire eliminated interview bias, but recall bias cannot be totally eliminated. Despite these limitations, the rates and levels of physical activity found in this study, particularly among girls, were low. Furthermore, even lower rates of exercise would be expected from school students outside the capital city of Muscat. Students in Oman do have opportunities for exercising, and therefore further tailoring of programmes and activities to surmount barriers and constraints would be expected to promote acceptable levels of physical activity. Maximizing the role of schools is indispensable. The focus of future studies should be on investigating the barriers to participation in physical education classes and exploring means of addressing these barriers.

\section{References}

1. Global status report on noncommunicable diseases, 2010. Geneva, World Health Organization, 2011.

2. Non-communicable diseases: country profile 2011. Geneva, World Health Organization, 2011.

3. Al-Lawati JA, Mabry R, Mohammed AJ. Addressing the threat of chronic diseases in Oman. Preventing Chronic Disease, 2008, 5:1-7.

4. Hill AG, Muyeed AZ, AI-Lawati JA. The mortality and health transitions in Oman: patterns and processes. Muscat, Oman, World Health Organization Regional Office for the Eastern
Mediterranean and the United Nations Children's Fund, 2000.

5. Lopez A et al. Global and regional burden of disease and risk factors, systematic analysis of population health data. Lancet, 2001, 360:1747-1757.

6. Mokdad AH et al. Prevalence of obesity, diabetes, and obesityrelated health risk factors. JAMA, 2003, 289:76-79.

7. Diabetes roadmap for the UN summit on non-communicable diseases: IDF member association consultation report. Brussels, Belgium, International Diabetes Federation, 2011. 
8. Misra A, Khurana L. Obesity and the metabolic syndrome in developing countries. Journal of Clinical Endocrinology and Metabolism, 2008, 93:S9-S30.

9. Global based health survey. Muscat, Oman, Ministry of Health, 2005.

10. Mehana M, Kilani H. Enhancing physical education in omani basic education curriculum: rationale and implications. International Journal for Cross-Disciplinary Subjects in Education, 2010, 1:99-104.

11. Al Kilani H, Waly M, Youssef R. Trends of obesity and overweight among college students in Oman: a cross sectional study. Sultan Qaboos University Medical Journal, 2012, 12:6976 .

12. Anshel $\mathrm{MH}$. Conceptualizing applied exercise psychology. Journal of the American Board of Sport Psychology, 2007 [online journal] (http://www.americanboardofsportpsychology. org/journalofabsp/tabid/1259/default.aspx, accessed 9 July 2013).

13. Dean AG, Sullivan KM, Soe MM. OpenEpi: open source epidemiologic statistics for public health, version 2.3.1 [online] (www. OpenEpi.com, accessed 9 July 2013).

14. Summary of education statistics 2010/2011. Muscat, Directorate of Statistics and Indicators, Ministry of Education, 2010.

15. Allison KR, Dweyer J, Makin S. Perceived barriers to physical activity among high school students. Preventive Medicine, 1999, 28:608-615.

16. Hovell MF et al. Identifying correlates of walking for exercise: an epidemiologic prerequisite for physical activity promotion. Preventive Medicine, 1989, 18:856-866.

17. Guidelines for data processing and analysis of the International Physical Activity Questionnaire (IPAQ). Short and long forms. November2005. IPAQ group [online] (http://www.ipaq.ki.se/ scoring.pdf, accessed 9 July 2013).

18. Ainsworth BE et al. The compendium of physical activities tracking guide. Phoenix, Arizona, Arizona State University, Healthy Lifestyles Research Center, College of Nursing and Health Innovation (https://sites.google.com/site/compendiumofphysicalactivities/home, accessed 9 July 2013).

19. Kesäniemi A et al. Advancing the future of physical activity guidelines in Canada: An independent expert panel interpretation of the evidence. International Journal of Behavioral Nutrition and Physical Activity, 2010, 7:41. doi:10.1186/1479-5868-7-41.

20. Al-Hazzaa HM, Musaiger AO; ATLS Research Group. Arab teens lifestyle study (ALT): objectives, design, methodology and implications. Diabetes, Metabolic Syndrome and Obesity, 2011, 4:417-426.
21. Obesity: preventing and managing the global epidemic. Report of a WHO consultation. Geneva, World Health Organization, 2000 (WHO Technical Report Series No. 894).

22. Belal AM, Al-Hinai HG. Community-based initiatives for prevention of non-communicable diseases: Nizwa healthy life style project planning and implementation experience in Oman. Sudanese Journal of Public Health, 2009, 4:225-228.

23. Haug H, Torsheim T, Samdal O. Local school policies increase physical activity in Norwegian secondary schools. Health Promotion International, 2009, 25:63-72.

24. Haug H, Torsheim T, Samdal O. Physical environmental characteristics and individual interests as correlates of physical activity in Norwegian secondary schools: The health behaviour in school-aged children study. International Journal of Behavioral Nutrition and Physical Activity, 2008, 5:47. doi:10.1186/14795868-5-47.

25. Martinez-Gomez D et al.; HELENA Study Group. Recommended levels of physical activity to avoid excess of body fat in European adolescents: the HELENA Study. American Journal of Preventive Medicine, 2010, 39:203-211.

26. Strong WB et al. Evidence based physical activity for schoolage youth. Journal of Pediatrics, 2005, 146:732-737.

27. Rosenberg DE et al. Brief scales to assess physical activity and sedentary equipment in the home. International Journal of Behavioral Nutrition and Physical Activity, 2010, 7:10. doi:10.1186/1479-5868-7-10.

28. Chen LJ, Haase AM, Fox KR. Physical activity among adolescents in Taiwan. Asia Pacific Journal of Clinical Nutrition, 2007, 16:354-361.

29. Daskapan A, Tuzun EH, Eker L. Perceived barriers to physical activity in university students. Journal of Sports Science and Medicine, 2006, 5:615-620.

30. Kelishadi $\mathrm{R}$ et al. Barriers to physical activity in a populationbased sample of children and adolescents in Isfahan, Iran. International Journal of Preventive Medicine, 2010, 1:131-137.

31. Gómez-López M, Gallegos AG, Extremera AB. Perceived barriers by university students in the practice of physical activities. Journal of Sports Science and Medicine, 2010, 9:374-381.

32. Al-Nuaim AA et al. The prevalence of physical activity and sedentary behaviours relative to obesity among adolescents from Al-Ahsa, Saudi Arabia: rural versus urban variations. Journal of Nutrition and Metabolism, 2012, doi:10.1155/2012/417589.

33. Biddle S, Gouda M. Analysis of children's physical activity and its association with adult encouragement and social cognitive variables. Journal of School Health, 1996, 66:75-78. 